\title{
Postnatal care generates phenotypic behavioural correlations in the Japanese quail
}

Pittet $\mathrm{F}^{1,2,3,4}$, Tyson $\mathrm{C}^{5}$, Herrington $\mathrm{J} \mathrm{A}^{2}$, Houdelier $\mathrm{C}^{1}$, Lumineau $\mathrm{S}^{1}$

${ }^{1}$ Université de Rennes, UMR 6552 « EthoS » : Ethologie Animale et Humaine, CNRS-

Université de Caen, Rennes, France

${ }^{2}$ Neuroscience and Behavior Unit, California National Primate Research Center, University of California Davis, United States

${ }^{3}$ Center for Evolution and Medicine, Arizona State University, Tempe, United States

${ }^{4}$ School for Human Evolution and Social Change, Arizona State University, Tempe, United States

${ }^{5}$ Department of Animal Science, University of California Davis, United States

Correspondence:

florent.pittet@gmail.com

Neuroscience and Behavior Unit, California National Primate Research Center, University of California in Davis, 1 Shield Avenue, Davis, CA, 95616.

ORCID: 0000-0002-1443-012X 


\section{Abstract}

Behavioural phenotypes can be highly constrained by interdependent behavioural traits. Studies in different taxa showed that these behavioural phenotypic correlations are not universal within a species and can differ between populations exposed to different environmental pressures. Empirical studies are required to better understand the relative contributions of longterm adaptive processes and direct ontogenetic mechanisms in the development of these phenotypic behavioural correlations.

In the present study, we investigated the role of postnatal nurturing care on the development of behavioural correlations in a precocial bird model, the Japanese quail (Coturnix coturnix japonica). We compared phenotypic correlations between two populations: 41 artificially reared birds (maternally deprived) and 36 birds fostered by unrelated females. Behavioural responses were measured at the age when birds naturally disperse, with three widely used behavioural tests to assess fearfulness and sociality: tonic immobility, open-field, and emergence tests.

Our results show that when quail chicks are reared by a foster mother, more phenotypic correlations appeared in the population including correlations within and across behavioural functions and between behavioural responses and chick mass. In contrast, chicks reared without a foster mother presented much fewer behavioural correlations and those were limited to functionally linked behaviours. Our results also highlight that the effect of mothering on phenotypic correlations is sex-specific, with a greater effect on males. We discuss the organisational role of parents on the development of behavioural correlations, the mechanisms likely to support this influence, as well as the reasons for sexual dimorphism.

\section{Key-words}

Behavioural correlations; behavioural development; maternal influence; precocial bird; sex differences. 


\section{Significance Statement}

Mothers deeply influence the behavioural development of their offspring during the postnatal stage. Whether maternal presence and nurturing behaviour also affect correlations between behavioural responses of their offspring at a population level remains underexplored and unclear. In the current study, we used an adoption procedure to demonstrate the critical role of maternal postnatal care for the development of behavioural correlations in a precocial bird model widely used for the study of behavioural ontogeny: the Japanese quail.

Our findings highlight that the presence of a maternally behaving female during early life promotes the development of correlations between behavioural responses both within and across behavioural functions in males but not in females. 


\section{Introduction}

Behavioural phenotypes can be highly constrained by interdependence between behavioural traits and the proximate and ultimate mechanisms responsible for behavioural phenotypic correlations have received extensive interest from behavioural ecologists (e.g. Sih et al. 2004; Réale et al. 2007). Such behavioural correlations are expected between functionally linked behaviours because they are presumed to be under the control of common neuroendocrinological structures. For instance, in a given population, phenotypic correlations are expected between different fear-related behaviours both within and between threatening situations due notably to a shared dependence on the responsiveness of the HypothalamicPituitary-Adrenocortical (HPA) axis (Macrì and Würbel 2006). Behavioural correlations can also occur between functionally differentiated behaviours (Sih et al. 2004; Bell 2007). The most documented example is the "aggressiveness / boldness" syndrome when, in a population, the most aggressive individuals in a social interaction are also the boldest ones, for example, towards a predator (Bell and Sih 2007; Sih et al. 2012).

How these behavioural correlations develop and why their structure varies between populations or species has recently received attention. Two main hypotheses have been advanced to explain phenotypic correlations between behavioural responses. Firstly, the constraint hypothesis considers the involvement of underlying proximate mechanisms (genetic or physiological) in limiting the phenotypical independence between different behavioural traits (Ketterson and Nolan 1999; Gosling 2001; Bell 2005; Dochtermann and Dingemanse 2013). Secondly, the adaptive hypothesis defends that behavioural correlations can emerge from environmentally induced effects. The adaptive hypothesis have received support from studies showing differences in phenotypic behavioural correlations between populations established in differing biotic environments (e.g. Dingemanse et al. 2007). Nevertheless, such effects could emerge from both genetic adaptation and through direct ontogenetic processes. Several studies 
demonstrated that exposing groups of individuals extracted from the same natural population, to varying levels of predation risk (Bell and Sih 2007) or conspecific presence (Urszán et al. 2015) can affect the development of phenotypic behavioural correlations. Such empirical studies nevertheless remain scarce (Guenther et al. 2014; Urszán et al. 2015), motivating further research to better understand how early life cues can constrain phenotypes in a population by affecting the occurrence and strength of behavioural correlations. In particular, during the early development period, such environmental cues are at the same time highly valuable and hardly accessible for species with extended parental care, making parental influence critical for an adapted modulation of offspring phenotype (Dufty et al. 2002; Marshall and Uller 2007). Yet, to our knowledge, the role played by parental nurturing behaviour on the development of behavioural correlations has not been explored.

Postnatal maternal care in mammals has been extensively studied to determine how differences between individuals or populations in the care provided to offspring could adaptively modulate the development of their behavioural phenotype (e.g. brown rat, Rattus norvegicus: Beery and Francis 2011; nonhuman primates: Fairbanks 1996; and see Groothuis and Maestripieri 2013). Precocial birds are just becoming targets of such studies (Japanese quail, Coturnix c. japonica: Pittet et al. 2014a; Domestic hen, Gallus gallus: Edgar et al. 2015). These precocial bird species exhibit exclusive maternal care during chick rearing and offer a very relevant alternative to mammals since females express the full repertoire of care towards unrelated individuals. In the context of adoption procedures, these species are consequently a valuable model to measure the exclusive influence of postnatal care on offspring behavioural ontogeny. For the specific question addressed here, it is critical to disentangle genetic and prenatal effects from these effects of postnatal behavioural care because these two former instances of maternal influence are also likely to induce behavioural correlations (genetic correlations: van Oers et al. 2005; prenatal influences: D'Amore et al. 2015). To illustrate the 
importance of maternal care for the development of behavioural phenotype in offspring, total maternal deprivation, also known as artificial rearing, remains a very robust procedure. Comparing the phenotype of artificially reared with that of adopted precocial birds highlights the strong and lasting consequences of mothering on the development of different traits of offspring personality with a focus on fearfulness (Japanese quail chicks: Bertin and RichardYris 2005; domestic chicks: Roden and Wechsler 1998; Shimmura et al. 2010; domestic pullets: Perré et al. 2002) and social behaviour (domestic chick: Fält 1978; domestic pullets: Perré et al. 2002; Japanese quail chicks: Bertin and Richard-Yris 2005). Such a context offers a unique opportunity to explore further the importance of ontogenetic processes in the development phenotypic behavioural correlations.

Using juvenile Japanese quails, our study examined the influence of the presence of a maternal female during the early postnatal period on the development of correlations between different behavioural responses related to fearfulness and social behaviour. We explored the effect of both mothering and sex of chicks on behavioural correlations using measures of tonic immobility, open-field, and emergence tests, three behavioural tests widely used to assess fearfulness and social reactivity in precocial birds (Boulay et al. 2013; Pittet et al. 2014c; Herrington et al. 2015) and across taxa (Boon et al. 2007; Toms et al. 2010; Nakayama et al. 2012; and see Forkman et al. 2007).

We hypothesized that adoption by an adult female should lead to stronger and more behavioural correlations through two main processes. First, we consider that the presence of an adult female constitutes a major enrichment, providing highly informative environmental cues to the adopted offspring. As argued by Trillmich et al. (2015), we consider that such cues should act in a "organisational manner" while the impoverishment (characterizing artificial rearing) should lead to less constrained phenotype (see Bengston et al. 2014 for an example with physical impoverishment). Second, in Japanese quail, the individual characteristics of care 
expressed by adoptive females (brooding behaviour, feeding and activity stimulations) simultaneously affect different behavioural responses across behavioural function (Pittet et al. 2014a), likely to induce correlations between these behaviours in a population level. Additionally, these care characteristics also influence offspring inter-individual differences in mass after independence (Pittet et al. 2012, 2014a). Such inter-individual differences in early growth and associated metabolism are proposed to support phenotypic correlations because individual differences in metabolic rates promote dependence between a collection of energetically costly behavioural responses (see Careau et al. 2008). Consequently, we expect less behavioural correlations and less correlations between behaviour and mass in artificially reared chicks whose individual growth is not constrained by early experience. Early life environmental factors can have highly differentiated consequences on male and female behavioural and neuro-endocrine development (Juraska 1984; McIntosh et al. 1999; Wigger and Neumann 1999; Francis et al. 2002; Barna et al. 2003; Oomen et al. 2009; van Hasselt et al. 2012; Pittet et al. 2014b; Aigueperse et al. 2018). Whether this is due to inherent sex differences in sensitivity or in behavioural plasticity, cross fostering studies reported that male birds are generally more affected by the adoptive mothers characteristics than females (Archer 1976; Vos 1995; Formanek et al. 2008). We consequently hypothesized that the influence of the adoptive mother on personality structure would be stronger among males than among females.

\section{Methods}

\section{Animals and housing conditions}

The quails in the current study were from a broiler line and originated from an industrial farm (Les Cailles de Chanteloup, Corps-Nuds, France). Animals were kept under $20 \pm 1^{\circ} \mathrm{C}$ with LD 12/12 light settings and dim green light during the dark phase. Food provided ad libitum 
was a high protein cereal diet in the form of pellet for chicks and granulates for adult females (VEGAM, Cesson-Sevigné, France).

Twenty-two 3-month-old females were used as adoptive mothers. Each bird was marked with a unique numbered tag attached to the wing when they arrived at the laboratory. They were placed in individual wire mesh breeding cages $(51 \times 40 \times 35 \mathrm{~cm})$ with a drinking trough and a feeder, 3 weeks before adoption began in order to allow the birds to habituate to environmental conditions.

Chicks came from 120 fertilized eggs artificially incubated in the laboratory. Incubation lasted 17 days when eggs were placed at $37.7^{\circ} \mathrm{C}$ with $45-50 \%$ humidity and one $45^{\circ}$ rotation every hour $\left(\right.$ Brinsea $^{\odot}$ Ova-Easy 380 Advance EX II). When chicks hatched, they were placed in groups of 40 individuals in wide plastic cages $(98 \times 35 \times 42 \mathrm{~cm})$ equipped with a feeder, a drinking trough and a heater $\left(38 \pm 1^{\circ} \mathrm{C}\right)$. As morphological sexual dimorphism appears only at 3 weeks (Mills et al. 1997), chicks were randomly distributed to each set and their sex was determined when they were 22 days old.

\section{Procedure}

Upon their arrival at the laboratory, the 22 adult females were distributed in cages so that two adult females were never in neighbouring cages. In the evening of the day of hatching, 86 chicks were randomly selected and distributed in the two different groups : 22 pairs of chicks were each placed with one of these females (hereafter "adopted" birds) and 21 pairs of chicks were placed in the other cages without mothers but each equipped with a heating lamp (38 \pm $1^{\circ} \mathrm{C}$, hereafter "artificially reared" birds). Heating lamps provided heat from an overhead ceramic bulb emitting in the non-visible far infra-red spectrum. The heating lamps were placed in the back of the cage while the light source was in the top front of the cage, resulting in similar light exposure in cages of adopted and artificially reared chicks. Pairs of mothered chicks were gently placed underneath an adult female that had been shut in a nest box $(18 \times 18 \times 18 \mathrm{~cm})$ an 
hour earlier and secured for the night, during which the chicks' vocal and physical solicitations induced the females to become maternal by the next morning when the boxes were opened (Bertin and Richard-Yris 2005). Following this procedure, adoptive females express the full maternal care repertoire by warming chicks, preening their feathers, stimulating their motor and feeding activity and by continuously communicating with them to keep the brood cohesive (Richard-Yris 1994). To prevent an experience bias from exploration of the cage on the first night, non-mothered chicks were also placed in similar boxes for their first night post-hatching. All boxes were opened and removed the next morning 30 minutes prior to the light phase. Maternal care was monitored on the first days of maternal periods, and mothers that did not express any warming behaviour of the chicks were excluded. Chicks that presented signs of hypothermia (closed eyes, trembling, low distress call pitch) and did not solicit the mother were excluded from the experiment and replaced by extra chicks of same age to keep a consistent brood of 2 chicks within all the cages. The replacement chicks were not tested for their behaviour. One female did not warm her chicks and was excluded from the experiment as well as her two chicks. Six mothered chicks and one non-mothered chick additionally showed signs of hypothermia on the first day following induction and were replaced. Sex composition of mothered birds was 18 males and 18 females; sex composition of non-mothered birds was 20 males and 21 females. Sex ratio did not differ between the two sets (mothered: $50.0 \%$ males, non-mothered: $48.8 \%$ males, $\left.X^{2}=0.01, P=0.9\right)$.

When the birds were 11 days old (age when they naturally disperse, Orcutt and Orcutt 1976), the mothers and the heating lamps were removed from the cages and they developed in pairs for 2 more weeks during which behavioural testing took place. The juvenile birds were weighed when they were 21 days old. 


\section{Behavioural tests}

The juvenile birds were tested in behavioural procedures established to characterize different aspects of behaviour in birds and mammals ( Forkman et al. 2007; Réale et al. 2007; Herrington et al. 2015). We used the tonic immobility test and two tests in unfamiliar environment with social isolation in which both emotional and social reactivity are expressed: the open-field test (open arena) and the emergence test (closed arena). Behavioural testing was completed by a single experimenter blind towards animal treatment.

Tonic immobility test: Tonic immobility is an anti-predator reflexive behaviour expressed in response to fear-inducing stimuli (Hazard et al. 2008). Duration and difficulty of induction are considered strong indexes of fearfulness in poultry (Herrington et al. 2015). The current study followed the protocol described by Jones (Jones 1986). Each bird was removed from its cage and tested at 14 days post-hatching. In a dark room, the test individual was placed on his back for $10 \mathrm{~s}$ in a U-shaped wooden cradle. Induction was considered successful when the tonic immobility (TI) duration was at least $10 \mathrm{~s}$ (with a maximum trial duration of $300 \mathrm{~s}$ ). Both TI duration and the number of failed inductions (with a maximum of 5) were noted.

Open-field test: Tested animals were individually placed in the centre of a nonagonal arena (walls were $60 \mathrm{~cm}$ high, $\sim 1 \mathrm{~m}^{2}$ ) on a linoleum floor, in the dark. The light was then switched on and the hidden experimenter noted, for 5 minutes, the number of distress calls emitted, and the number of steps taken by the subject. Birds were tested between 15 and 16 days post-hatching. Activity rate in the open-field is considered negatively correlated with general fearfulness and the frequency of calls emitted when isolated reflects the level of social reactivity of birds (Bertin and Richard-Yris 2005).

Emergence test: At 17 days post-hatching, juvenile birds were removed from their home cage and transported in a covered, wooden box $(18 \times 18 \times 18 \mathrm{~cm})$. This box was then placed on one side of the apparatus: a large and well-lighted wooden box $(62 \times 60 \mathrm{~cm}$ and $33 \mathrm{~cm} \mathrm{high})$ 
with wood-shavings on the floor and a glazed observation window. The door of the transport box was opened after one minute and the experimenter noted the time the tested bird needed to emerge from the box to reach the cage (full body outside of the box). Once the animal was in the test cage, the transport box was closed, and the observer noted the number of distress calls emitted by the subject. A longer emergence latency is considered to reflect higher fearfulness and the number of distress calls is considered to reflect social reactivity to isolation (Jones et al. 1991; Bertin and Richard-Yris 2005).

\section{Statistical analyses}

If not otherwise detailed, all the statistical analyses were performed in $\mathrm{R}$ version 3.5.1 ( $\mathrm{R}$ core team 2018). Behavioural variables not reaching the normality assumptions were transformed using either log or box-cox transformations. We first tested for the importance of keeping adoptive female ID as a random effect in our analyses. We fitted models for each of the 7 variables with and without a random structure for adoptive female ID and compared the fit through Likelihood Ratio tests (LRT) and Akaike information criteria (AIC, Akaike 1974). Similar methods for determining the importance of random effects have been used elsewhere (e.g. Ezard et al. 2009; Moreno et al. 2019). LRT indicated that the identity of the adoptive mother could be dropped from the models due to a negligible change in model fit (LRT, for all 7 traits: $p>0.4$ ), which was further confirmed by an inflation of AIC when including foster female ID (supplementary Table 1).

We studied the influence of mothering on behavioural correlations by comparing correlations between artificially reared and adopted birds. Because statistical methods for formal comparison of correlations only allow for pair-comparisons, the influence of mothering on personality structure was first studied for both sexes combined and then again for each sex separately. We first identified the structure of behavioural phenotypes of each subset by describing significant correlations as in Kooij et al. 2002; Janczak et al. 2003; Bell and Stamps 
2004; Kanda et al. 2012; Wilson and Krause 2012; Guenther and Trillmich 2013; Guenther et al. 2014; Taylor et al. 2014; van Overveld et al. 2014; Wuerz and Krüger 2015. Correlations between each pair of dependent variables (the 6 behavioural variables and the mass of birds) were calculated using Pearson correlation tests and generated $95 \%$ confidence intervals through bootstrapping with 5000 iterations (function cor.ci in the package "psych" V1.8.10).

In addition, we statistically compared the structure of behavioural phenotypes by (1) comparing covariance for each pair of variables and (2) comparing the covariance matrices structure between adopted and artificially reared chicks. (1) First, in order to compare pair-wise variable associations between subsets, we first calculated the variance-covariance matrix for each pair of dependent variables using ASreml-R 3.0 (Butler et al. 2009). We then calculated the arithmetic difference between these matrices to yield a 'difference matrix' and used parametric bootstrapping in order to estimate $95 \%$ confidence intervals around each variancecovariance measure. Behavioural associations between artificially reared and adopted chicks were deemed statistically different when the $95 \%$ confidence interval did not overlap zero (see Houslay et al. 2018 for analysis details). (2) We also compared the structure of the covariance matrices with Common Principal Component analysis using the CPC program (CPC, Phillips and Arnold 1999). CPC analysis is a robust method for comparison of personality structure (Budaev 1999; Han and Brooks 2013). The analysis consists of covariance matrices structure comparison in a hierarchical fashion, from unrelated matrices to common principal components (same principal components but different eigen values), to proportional matrices (same principal components but proportional eigen values), to similar matrices. The nature of the relation between the matrices corresponds to the model resulting in the lowest Akaike information criterion. The nature of the relation between the matrices was further confirmed by the "jump-up" approach, consisting in the test of each level of the hierarchy against "unrelated structure”, (Phillips and Arnold 1999; Han and Brooks 2013). 


\section{Data availability}

The dataset analysed during the current study is available from the corresponding author on reasonable request.

\section{Results}

\section{General effect of mothering on the structure of behavioural phenotype}

We first tested the correlations between each pair of variables separately in artificially reared and in adopted chicks. More significant correlations appeared in adopted chicks: among 21 tested correlations, 10 were significant in adopted birds and 2 in artificially reared birds $\left(X^{2}\right.$ $=9.02, p=0.002)$. Significant correlations among artificially reared chicks were only found between functionally linked behaviours: the latency to move in the emergence test was negatively correlated with the number of steps taken in the open-field, and the number of distress calls emitted in the emergence test was positively correlated with the number of calls emitted in the open-field (Fig. 1). In contrast, adopted chicks displayed significant correlations between both functionally linked behaviours, non-functionally linked behaviours and between mass and several behaviours including TI duration and induction, steps taken in the open-field and calls emitted in both open-field and emergence tests (Fig. 1).

Pairwise comparisons of correlations between sets revealed significant differences for 6 correlations (Fig. 1, Table 1). These correlations were all significant in adopted chicks while no relation between variables could be identified in the artificially reared chicks. These correlations included relationship between mass and several behavioural variables (TI inductions, TI duration and number of calls emitted in the emergence test), as well as relationship between TI inductions and duration and between TI duration and number of calls emitted in the emergence test.

CPC analysis additionally revealed that the structural relation between matrices from artificially reared and adopted females was best described as unrelated $\left(\Delta_{\text {AIC }}\right.$ (unrelated-equal) $=-$ 
3.48, Fig. 4). Jump-up approach confirmed that structure of matrices was unrelated across treatments (CPC test: equal Vs unrelated matrices: $X^{2}=59.45, \mathrm{df}=28, p=0.0005$, proportional Vs unrelated: $X^{2}=58.64, \mathrm{df}=27, p=0.0004$, common principal components Vs unrelated: $X^{2}$ $=47.79, \mathrm{df}=21, p=0.0007)$.
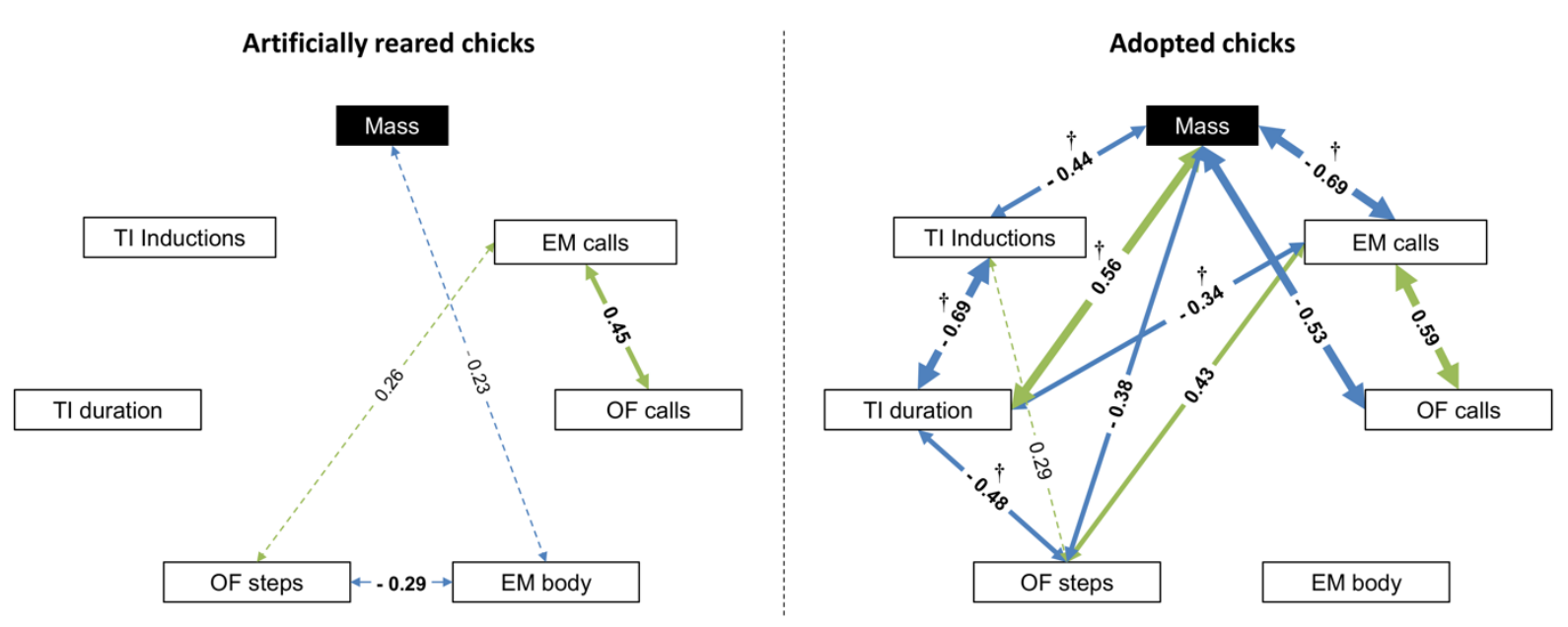

Fig. 1 Structure of behavioural phenotype of artificially reared (left, $n=41)$ and adopted chicks (right, $n=36$ ). Correlations between the 6 measured behaviours and the mass of birds. Solid lines represent significant correlations (95\% confidence interval not spanning $0, p<0.05$ ), dashed lines represent trends $(p<0.08)$. Line thickness depends on the absolute value of correlation coefficients (1 point: $|\mathrm{r}|<0.3,3$ points: $|\mathrm{r}|<0.5,5$ points: $|\mathrm{r}|<0.7$ ). Correlation coefficients are displayed on the lines, in bold for significant correlations. When displayed on correlation coefficient, $\uparrow$ indicates significantly different variables associations between sets, as revealed by the D matrix (Table 1). TI: tonic immobility, OF: open-field test, EM: emergence test

\section{Influence of mothering on the structure of behavioural phenotype in female and male}

offspring

In adopted females as well as in artificially reared females, only 3 correlations were significant, and only one correlation was common in both populations for a positive relation between the number of distress calls emitted in the open-field and emergence tests (Fig. 2). In artificially reared females, the number of steps taken in the open-field was negatively correlated with the time required to leave the shelter in the emergence test and positively correlated with the number of distress calls emitted in the emergence test (Fig. 2). Adopted females presented 
a negative correlation between mass and the number of distress calls emitted in the open-field and a negative correlation between tonic immobility duration and number of inductions needed to express tonic immobility (Fig. 2).

Table 1 Difference variance-covariance matrix for comparisons of artificially reared chicks and adopted chicks. Differences in variances appear on the diagonals, and differences in covariances off-diagonal; 95\% confidence intervals are taken from differences across 5,000 bootstrapped replicate pairs for each D matrix. Bold values indicate elements where $95 \%$ confidence intervals do not span zero. TI: tonic immobility, OF: open-field test, EM: emergence test

\begin{tabular}{|c|c|c|c|c|c|c|c|}
\hline & Mass & TI duration & TI induction & OF steps & OF calls & EM body & EM calls \\
\hline Mass & $\begin{array}{c}-0.52 \\
(-1.13,0.06)\end{array}$ & $\begin{array}{c}-0.65 \\
(-1.05,-0.26)\end{array}$ & $\begin{array}{c}0.63 \\
(0.14,1.12)\end{array}$ & $\begin{array}{c}0.32 \\
(-0.14,0.75)\end{array}$ & $\begin{array}{c}0.34 \\
(-0.07,0.75)\end{array}$ & $\begin{array}{c}-0.16 \\
(-0.58,0.26)\end{array}$ & $\begin{array}{c}0.61 \\
(0.21,1.03)\end{array}$ \\
\hline TI duration & & $\begin{array}{c}-0.11 \\
(-0.55,0.35)\end{array}$ & $\begin{array}{c}0.58 \\
(0.11,1)\end{array}$ & $\begin{array}{c}0.45 \\
(0.04,0.86)\end{array}$ & $\begin{array}{c}0.08 \\
(-0.26,0.44)\end{array}$ & $\begin{array}{c}-0.1 \\
(-0.46,0.28)\end{array}$ & $\begin{array}{c}0.35 \\
(0.02,0.7)\end{array}$ \\
\hline TI induction & & & $\begin{array}{c}-0.49 \\
(-1.17,0.17)\end{array}$ & $\begin{array}{c}-0.25 \\
(-0.74,0.24)\end{array}$ & $\begin{array}{c}-0.14 \\
(-0.57,0.27)\end{array}$ & $\begin{array}{c}-0.05 \\
(-0.5,0.38)\end{array}$ & $\begin{array}{c}-0.13 \\
(-0.53,0.26)\end{array}$ \\
\hline OF steps & & & & $\begin{array}{c}-0.12 \\
(-0.83,0.45)\end{array}$ & $\begin{array}{c}0.08 \\
(-0.37,0.46)\end{array}$ & $\begin{array}{c}-0.32 \\
(-0.79,0.11)\end{array}$ & $\begin{array}{c}-0.05 \\
(-0.5,0.33)\end{array}$ \\
\hline OF calls & & & & & $\begin{array}{c}0.13 \\
(-0.45,0.66)\end{array}$ & $\begin{array}{c}0.01 \\
(-0.39,0.43)\end{array}$ & $\begin{array}{c}0.09 \\
(-0.31,0.48)\end{array}$ \\
\hline EM body & & & & & & $\begin{array}{c}0.07 \\
(-0.54,0.68)\end{array}$ & $\begin{array}{c}0.04 \\
(-0.34,0.43)\end{array}$ \\
\hline EM calls & & & & & & & $\begin{array}{c}0.28 \\
(-0.23,0.78)\end{array}$ \\
\hline
\end{tabular}

Pairwise comparisons of behavioural associations between artificially reared and adopted female chicks did not reveal any significant differences (all confidence intervals spanning 0, Table 2). CPC analysis additionally revealed that the structural relation between matrices from artificially reared and adopted females was best described as identical $\left(\Delta_{\mathrm{AIC}}\right.$ $($ unrelated-identical $)=14.99$, Fig. 4). Jump-up approach confirmed that structure of matrices was similar across treatments (test of equal matrices Vs unrelated matrices: $X^{2}=40.01, \mathrm{df}=28, p>$ $0.05)$ 

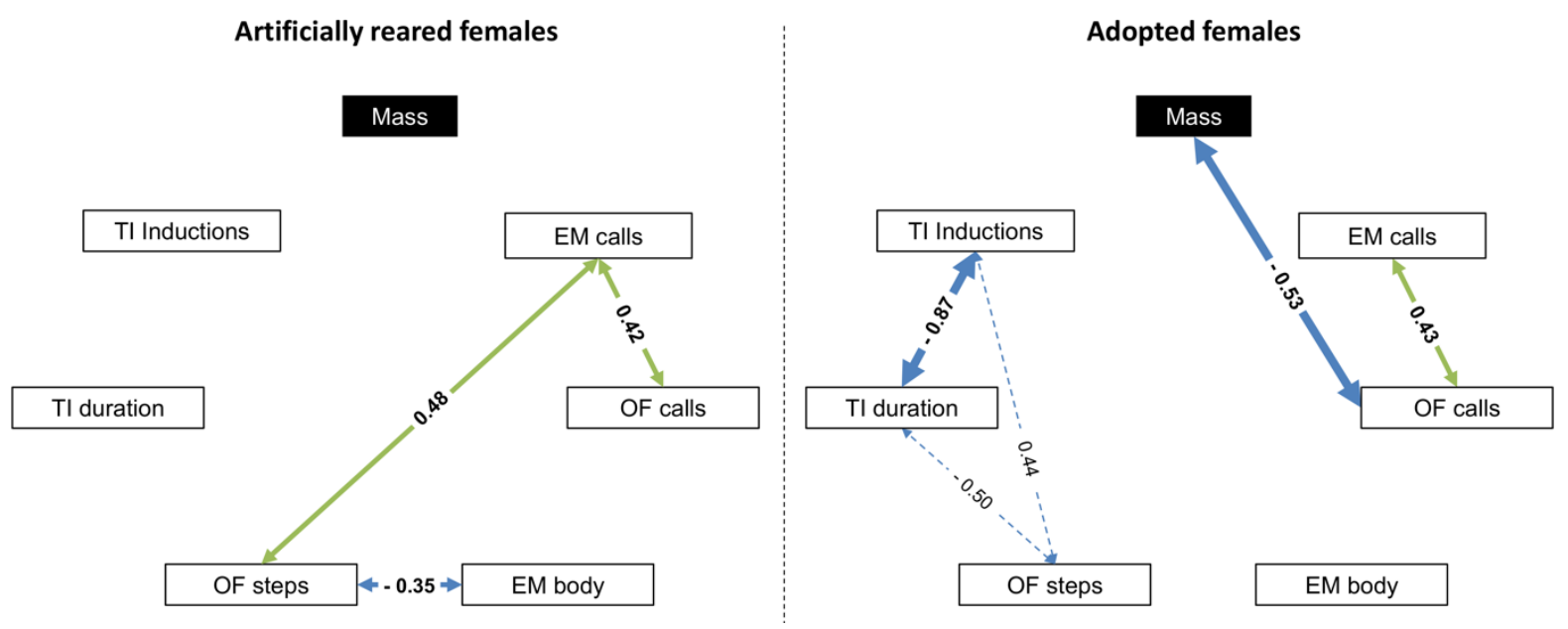

Fig. 2 Structure of behavioural phenotype of artificially reared (left, $n=21$ ) and adopted (right, $n=18)$ females. Solid lines represent significant correlations $(95 \%$ confidence interval not spanning $0, p<0.05)$, dashed lines represent trends $(p<0.08)$. Line thickness depends on the absolute value of correlation coefficients (1 point: $|\mathrm{r}|<0.3,3$ points: $|\mathrm{r}|<0.5,5$ points: $|\mathrm{r}|<0.7$ ). Correlation coefficients are displayed on the lines, in bold for significant correlations. No variables associations were significantly different between sets according to the D matrix (Table 2). TI: tonic immobility, OF: open-field test, EM: emergence test

Table 2 Difference variance-covariance matrix for comparisons of artificially reared females and adopted females. Differences in variances appear on the diagonals, and differences in covariances are reported off-diagonal; 95\% confidence intervals are taken from differences across 5,000 bootstrapped replicate pairs. All the elements spanned 0 indicating no significant differences in variables associations. TI: tonic immobility, OF: open-field test, EM: emergence test

\begin{tabular}{|c|c|c|c|c|c|c|c|}
\hline & Mass & TI duration & TI induction & OF steps & OF calls & EM body & EM calls \\
\hline Mass & $\begin{array}{c}0.04 \\
(-0.44,0.65)\end{array}$ & $\begin{array}{c}-0.44 \\
(-0.44,0.08)\end{array}$ & $\begin{array}{c}0.48 \\
(-0.48,1)\end{array}$ & $\begin{array}{c}0.11 \\
(-0.06,0.69)\end{array}$ & $\begin{array}{c}0.29 \\
(-0.48,0.89)\end{array}$ & $\begin{array}{c}-0.16 \\
(-0.44,0.35)\end{array}$ & $\begin{array}{c}0.21 \\
(-0.44,0.6)\end{array}$ \\
\hline TI duration & & $\begin{array}{c}-0.03 \\
(-0.48,0.87)\end{array}$ & $\begin{array}{c}0.74 \\
(-0.39,1.53)\end{array}$ & $\begin{array}{c}0.67 \\
(-0.44,1.39)\end{array}$ & $\begin{array}{c}0.18 \\
(-0.39,0.87)\end{array}$ & $\begin{array}{c}-0.36 \\
(-0.48,0.3)\end{array}$ & $\begin{array}{c}0.16 \\
(-0.44,0.63)\end{array}$ \\
\hline TI induction & & & $\begin{array}{c}-0.44 \\
(-0.36,0.52)\end{array}$ & $\begin{array}{c}-0.48 \\
(-0.44,0.28)\end{array}$ & $\begin{array}{c}-0.39 \\
(-0.36,0.28)\end{array}$ & $\begin{array}{c}0.33 \\
(-0.48,1)\end{array}$ & $\begin{array}{c}0.13 \\
(-0.48,0.62)\end{array}$ \\
\hline OF steps & & & & $\begin{array}{c}-0.11 \\
(-0.48,0.99)\end{array}$ & $\begin{array}{c}0.22 \\
(-0.06,1)\end{array}$ & $\begin{array}{c}-0.17 \\
(-0.39,0.53)\end{array}$ & $\begin{array}{c}0.61 \\
(-0.48,1.23)\end{array}$ \\
\hline OF calls & & & & & $\begin{array}{c}-0.24 \\
(-0.44,0.79)\end{array}$ & $\begin{array}{c}0.09 \\
(-0.36,0.77)\end{array}$ & $\begin{array}{c}0.18 \\
(-0.39,0.74)\end{array}$ \\
\hline EM body & & & & & & $\begin{array}{c}-0.06 \\
(-0.06,0.81)\end{array}$ & $\begin{array}{c}-0.06 \\
(-0.36,0.44)\end{array}$ \\
\hline EM calls & & & & & & & $\begin{array}{c}0.76 \\
(-0.06,1.43)\end{array}$ \\
\hline
\end{tabular}

Artificially reared males only presented one significant correlation between mass and the latency to leave the shelter in the emergence test. Adopted males, however, presented more 
significant correlations $\left(X^{2}=10.5, p=0.001\right)$ as 10 out of the 21 tested correlations were significant.

Pairwise comparisons of variables associations between artificially reared and adopted male chicks revealed that 4 correlations, all of which appeared in adopted chicks only, significantly differed between the sets and concerned the relation between mass and TI duration, between mass and calls emitted in the emergence test, between TI duration and calls in the emergence test and between steps taken in the open-field and calls emitted in the emergence test (Fig. 3, Table 3). PCP analysis revealed that the structural relation between matrices from artificially reared and adopted males was best described as unrelated $\left(\Delta_{\text {AIC }}\right.$ (unrelated-identical) $=$ 14.14, Fig. 4). Jump-up approach confirmed that structure of matrices was unrelated across treatments (CPC test: equal Vs unrelated matrices: $X^{2}=70.14, \mathrm{df}=28, \mathrm{P}<0.0001$, proportional Vs unrelated: $X^{2}=67.36, \mathrm{df}=27, p<0.0001$, common principal components Vs unrelated: $X^{2}$ $=51.54, \mathrm{df}=21, p=0.0002)$.
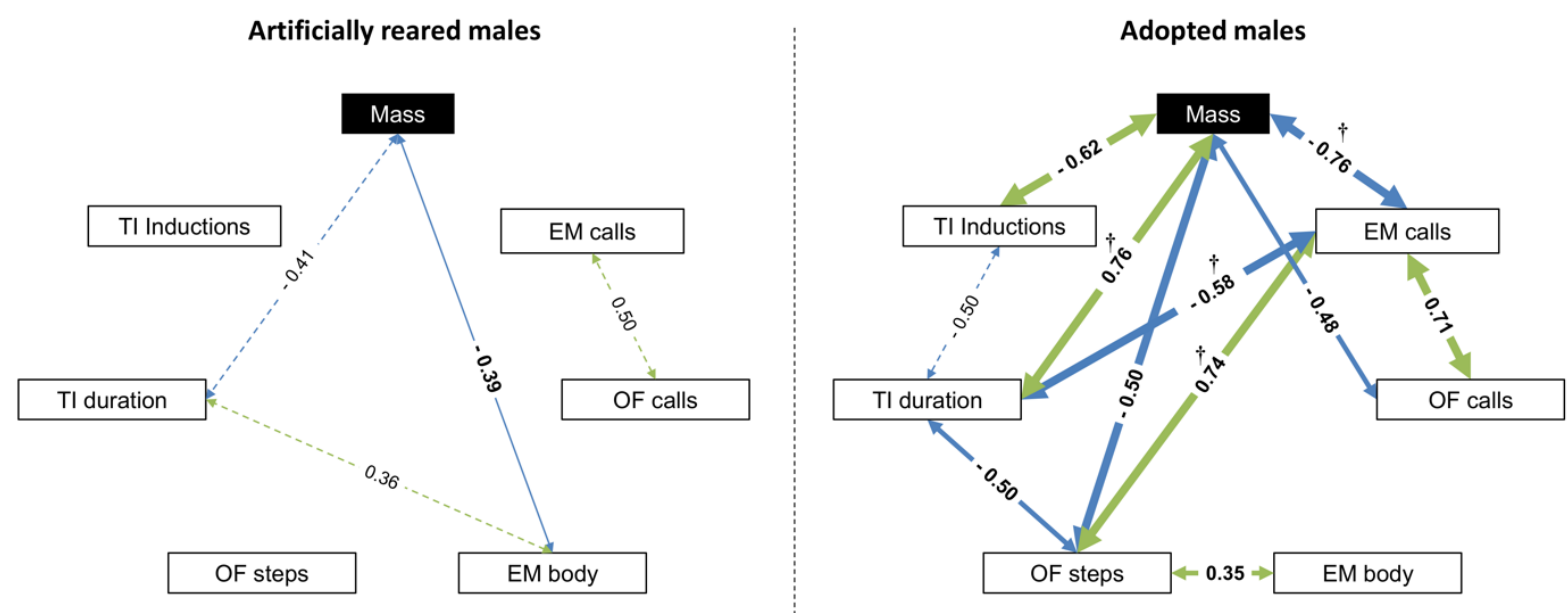

Fig. 3 Structure of behavioural phenotype of artificially reared (left, $n=20$ ) and adopted (right, $n=18)$ males. Solid lines represent significant correlations $(95 \%$ confidence interval not spanning $0, p<0.05)$, dashed lines represent trends $(p<0.08)$. Line thickness depends on the absolute value of correlation coefficients (1 point: $|\mathrm{r}|<0.3,3$ points: $|\mathrm{r}|<0.5,5$ points: $|\mathrm{r}|<0.7$ ). Correlation coefficients are displayed on the lines, in bold for significant correlations. When displayed on correlation coefficient, $\dagger$ indicates significantly different variables associations between sets, as revealed by the D matrix (Table 3). TI: tonic immobility, OF: open-field test, EM: emergence test 
Table 3 Difference variance-covariance matrix for comparisons of artificially reared males and adopted males. Differences in variances appear on the diagonals, and differences in covariances off-diagonal; 95\% confidence intervals are taken from differences across 5,000 bootstrapped replicate pairs. Bold values indicate elements where $95 \%$ confidence intervals do not span zero. TI: tonic immobility, OF: open-field test, EM: emergence test

\begin{tabular}{|c|c|c|c|c|c|c|c|}
\hline & Mass & TI duration & TI induction & OF steps & OF calls & EM body & EM calls \\
\hline Mass & $\begin{array}{c}-1.08 \\
(-2.17,0.03)\end{array}$ & $\begin{array}{c}-0.86 \\
(-1.49,-0.3)\end{array}$ & $\begin{array}{c}0.78 \\
(-0.03,1.62)\end{array}$ & $\begin{array}{c}0.52 \\
(-0.16,1.21)\end{array}$ & $\begin{array}{c}0.39 \\
(-0.1,0.83)\end{array}$ & $\begin{array}{c}-0.16 \\
(-0.8,0.5)\end{array}$ & $\begin{array}{c}1 \\
(0.24,1.84)\end{array}$ \\
\hline TI duration & & $\begin{array}{c}-0.2 \\
(-0.59,0.25)\end{array}$ & $\begin{array}{c}0.42 \\
(-0.06,0.91)\end{array}$ & $\begin{array}{c}0.22 \\
(-0.2,0.66)\end{array}$ & $\begin{array}{c}-0.01 \\
(-0.33,0.31)\end{array}$ & $\begin{array}{c}0.17 \\
(-0.25,0.6)\end{array}$ & $\begin{array}{c}0.53 \\
(0.04,0.98)\end{array}$ \\
\hline TI induction & & & $\begin{array}{c}-0.54 \\
(-1.46,0.45)\end{array}$ & $\begin{array}{c}-0.02 \\
(-0.61,0.59)\end{array}$ & $\begin{array}{c}0.11 \\
(-0.35,0.57)\end{array}$ & $\begin{array}{c}-0.43 \\
(-1.07,0.23)\end{array}$ & $\begin{array}{c}-0.39 \\
(-1.02,0.27)\end{array}$ \\
\hline OF steps & & & & $\begin{array}{c}-0.14 \\
(-0.83,0.57)\end{array}$ & $\begin{array}{c}-0.06 \\
(-0.51,0.37)\end{array}$ & $\begin{array}{c}-0.47 \\
(-1.06,0.08)\end{array}$ & $\begin{array}{c}-0.72 \\
(-1.37,-0.09)\end{array}$ \\
\hline OF calls & & & & & $\begin{array}{c}0.49 \\
(-0.06,1.07)\end{array}$ & $\begin{array}{c}-0.08 \\
(-0.52,0.43)\end{array}$ & $\begin{array}{c}-0.01 \\
(-0.54,0.48)\end{array}$ \\
\hline EM body & & & & & & $\begin{array}{c}0.2 \\
(-0.68,1.05)\end{array}$ & $\begin{array}{c}0.15 \\
(-0.48,0.72)\end{array}$ \\
\hline EM calls & & & & & & & $\begin{array}{c}-0.21 \\
(-0.98,0.68)\end{array}$ \\
\hline
\end{tabular}

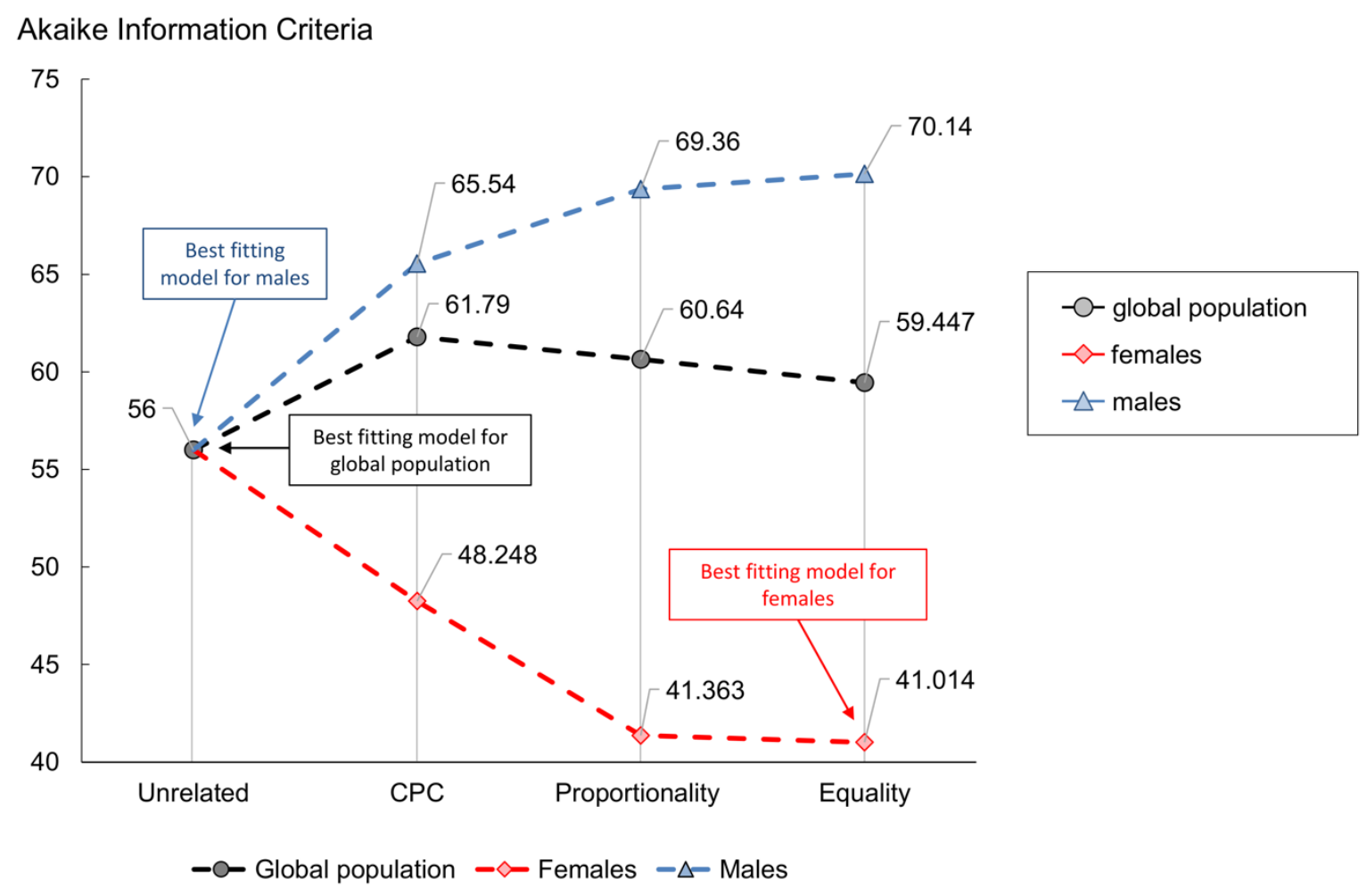

Fig. 4 Structural comparison of covariance matrices through common principal component analysis. Based on AIC model selection, relationship between the structure of matrices of artificially reared and adopted chicks is best described as unrelated for the global population and for males, and as equal for females 


\section{Discussion}

Our study demonstrated that phenotypic behavioural correlations are influenced by postnatal care. We showed that the population of chicks reared by an unrelated adoptive female disperse with more behavioural correlations than chicks reared artificially with total maternal deprivation. Additionally, our study indicates that the presence of a surrogate mother during development has a strong effect on the emergence of behavioural correlations in males while no significant differences on behavioural correlations were found between adopted and artificially reared females. To our knowledge, the results from the current study are the first demonstration of the significant role of postnatal care on the development of phenotypic behavioural correlations.

As hypothesized, the presence of a surrogate mother during early life induced the development of more correlations between behavioural responses within and across behavioural functions, as well as between behavioural responses and mass of chicks. Artificially reared chicks exhibited phenotypes unconstrained by behavioural correlations. Interestingly, the artificially reared chicks in the current study did not even display the correlation between the ease of tonic immobility induction and its duration, which is commonly acknowledged (Webster et al. 1981; Cockrem 2007; Edelaar et al. 2012). The lack of correlations between artificially reared chicks' behavioural responses was not due to less variable responses (e.g. tonic immobility duration and distress calls emitted in the emergence test were more variable among artificially reared chicks, Supplementary Table 8). Similarly, this result is not due to a lesser reactivity of artificially reared chicks in the different tests because they exhibited greater fear and greater social distress when isolated (supplementary Table 8), which is consistent with previous studies (Roden and Wechsler 1998; Perré et al. 2002; Shimmura et al. 2010; Pittet et al. 2014c). 
The major factor responsible for the development of behavioural correlations is most likely to be the presence of a nurturing adult female and its interaction with the chicks. We propose that the presence of a maternal female could be considered as a source of enrichment, exposing chicks to a collection of consistent stimulations and challenges requiring fast, contingent behavioural responses. Lickliter and Harshaw (2010) emphasize the importance of contingency in early experience. The artificially reared birds were not allowed the same contingent responses as the maternally reared birds, which may prevent them from developing specific responses to challenging situations, and to generalize such responses across contexts. From a proximate point of view, variation in the stimulations from the caregiver is a strong source of neurophysiological organising, modulating the development of both brain and physiological structures acting later on fear, social and reproductive behavioural responses (Francis and Meaney 1999; Nephew and Murgatroyd 2013; Morrison et al. 2014). These maternal organisational influences are necessarily augmented by the highly consistent individual characteristics of mothering styles adoptive female quails exhibit throughout the mothering period (Pittet et al. 2014a).

Our previous studies highlighted that mothers (including adoptive females) show consistent interindividual differences in two main dimensions of their care with large organisational effects on offspring phenotype: the amount of rejection (as opposed to brooding) of offspring which increases offspring social motivation and delays their mass gain, and the amount of aggressiveness (pecking chicks), which increases their fear responses and also delays mass gain (Pittet 2012). Variability and high consistency in these maternal dimensions are proposed to support behavioural correlations within behavioural functions in the population of adopted chicks. Nevertheless, these two dimensions of maternal care are independent (Pittet et al. 2014a) which means that correlations between fear and social traits in offspring are not due to covariation between these two components of mothering styles. It is nevertheless possible 
that mothers induce correlations across context through conditioning mechanisms by rewarding or sanctioning specific behavioural combinations. For instance, correlations between locomotor and vocal response to distress might emerge from mothers being more prone to care for chicks expressing a balanced combination of these behaviours.

It is also very likely that offspring behavioural correlations across context rely on individual differences in neurophysiology or metabolism developing under the influence of postnatal care and constraining dependence between behaviours after dispersion. One of the most documented effects of postnatal care on neurophysiological development of offspring is the influence of parental stimulations on the organisation of the HPA axis (Gunnar 1998; Francis and Meaney 1999; Champagne et al. 2003). Differences in HPA axis responses are considered as responsible for reactivity syndromes observed across behavioural functions (Koolhaas et al. 1999). Additionally, variability in HPA axis reactivity may support links between behavioural responses and metabolism / mass (Careau et al. 2008). Here, adopted individuals not only show correlations between their behavioural responses across different challenging situations (antipredator response in the tonic immobility test, motor and vocal reaction in novel environments and social isolation) but also display strong correlations between their mass and behaviour. It is consequently likely that the organisational effects of mothering on HPA reactivity underlies the differences observed in behavioural correlations between adopted and artificially reared chicks. In particular, it is possible that the impoverished experiences of artificially reared chicks in the first two weeks after hatching results in an absence of specific behavioural responses associated with variation in HPA reactivity later in life. Accordingly, two studies in artificially reared precocial birds reported an absence of correlation between glucocorticoid levels, mass, and behaviour (e.g. Mignon-Grasteau et al. 2003; Hope et al. 2018). 
Adoption had a stronger effect on behavioural correlations in males. Two main nonexclusive mechanisms might underly this result. First, males and females can show inherent neurophysiological dimorphism making them differently sensitive towards similar parental stimulations (Juraska 1984; McIntosh et al. 1999; Wigger and Neumann 1999; Francis et al. 2002; Barna et al. 2003; Oomen et al. 2009; van Hasselt et al. 2012; Pittet et al. 2014b). Several studies of the consequences of early life social factors on behavioural development reported stronger effects in male than in female birds (Archer 1976; Vos 1995; Formanek et al. 2008). Second, mothers can interact differently with males and females and their investment is often unbalanced in favour of sons in a variety of taxa (Moore and Morelli 1979; Hogg et al. 1992; Cameron and Linklater 2000) including monomorphic bird species (Stamps et al. 1987; Harding et al. 2009). A recent study in Japanese quail revealed that, similarly, mothers express a greater quantity and quality of care towards males who spend more time close to their mothers (Aigueperse et al. 2019). It is consequently possible that the stronger impact of mothering on males' behavioural correlations is related to their privileged interactions with the caregiver. From a ultimate point of view, it was proposed that these sex-related differences in behavioural correlations result from differentiated life histories and associated selective pressures for males and females (Fresneau et al. 2014). Males' more constrained behavioural phenotypes are proposed to be necessary for sexual selection (see Bell et al. 2009; Schuett et al. 2010) while in females, a more flexible phenotype is proposed to be necessary for an adapted maternal response to offspring needs and environmental fluctuations (Schwagmeyer and Mock 2003; Nakagawa et al. 2007). Our results suggest that behaviours related to different function are more tightly correlated in males because these behaviours are dependent upon individual mass. It is consequently likely that in Japanese quails, and possibly in other species presenting exclusive postnatal care by mothers, females' flexible reproductive strategies require more independence between behavioural responses and somatic resources. 


\section{Conclusion}

Taken together, the results of the present study further improve our understanding of maternal postnatal influences on behavioural ontogeny, highlighting the importance of the presence of a caregiver for the development of behavioural correlations. This result more broadly confirms that the absence of informative cues in impoverished environments result in reduced phenotypic constraints and more unpredictable responses. The current study focused on behavioural correlations of offspring at the age when they disperse, and when their behavioural responses are crucial for their survival (Hope et al. 2018). Further work is required to determine how early life factors such as maternal deprivation affect behavioural correlations across the lifespan, as such correlations can change during later ontogenetic stages (e.g. Brommer and Class 2015). In particular, it is uncertain whether behavioural correlations would develop with later experience of richer environment or that, alternatively, the environment does not affect behavioural correlations on these later stages due to reduced plasticity. Furthermore, we here focused on phenotypic behavioural correlations in the populations and did not study animal personalities, which would require repeated measures to assess both consistency of responses and within individual correlations. Further work is consequently required to determine if, similarly, the presence of a caregiver also increases individual consistency.

Our results additionally reveal a danger for the interpretation and generalisation of behavioural results from studies conducted in laboratories and other captive environments with artificial rearing. Indeed, if such impoverishment prevents the development of behavioural correlations, then the behavioural responses measured (e.g. tonic immobility) can hardly be used to characterize a trait (e.g. fearfulness) in the population. These results are finally of importance for animal welfare, as they suggest that artificial rearing - or reduced opportunities of interaction with adults - which are routinely used in intensive breeding, prevents the 
development of adapted and predictable behavioural strategies yet necessary to cope with the physical and social challenges characterizing these environments (Laurence et al. 2015).

\section{Acknowledgments}

The authors would like to thank Tom Houslay for his critical statistical guidance and coding support. We thank Christophe Petton for his help rearing and maintaining the birds. We are grateful to Pr. Judy Stamps for her very helpful comments at the early stages of this work. We also thank the two anonymous reviewers and the editors whose suggestions helped improve this manuscript.

\section{Compliance with ethical standards}

\section{Funding}

No specific funding was involved to support the current work

\section{Conflict of interest}

No conflict of interests declared

\section{Ethical approval}

All experiments were approved by the departmental direction of veterinary services (Ille et Vilaine, France, Permit number 005283) and were performed in accordance with the European Communities Council Directive of 24 November 1986 (86/609/EEC). Our breeding procedure and tests were approved by the regional ethics committee (agreement number: R2011-SLU-02).

A particular care was taken to ensure animal welfare in this study. Adult females were transported by car in aluminium crates $(70 \times 30 \mathrm{~cm}$ and $22 \mathrm{~cm}$ high), each containing six individual boxes. The temperature was $20^{\circ} \mathrm{C}$ during transportation and the journey lasted 20 min. Once at the laboratory, females used as adoptive mothers are routinely housed singly (Bertin and Richard-Yris 2005; Houdelier et al. 2011) because, under natural conditions, they incubate and care for their chicks alone (Guyomarc'h and Saint-Jalme 1986). We did not provide hiding places because we needed to monitor the chicks every day without disturbing the brood. Cages were behind one-way mirrors to limit disturbance, and we checked that the 
females showed no stereotypies, distress calls or flight attempts, and that they carried out normal comfort behaviours such as dust bathing, which was facilitated by plastic netting covering the cage floor.

We observed no cases of maternal abuse and one case of maternal induction failure resulting in the mother not warming the chicks once out of the induction box. M and NM chicks showing signs of hypothermia were all put under a heater in plastic cages $(98$ X $35 \mathrm{~cm}$ and 42 $\mathrm{cm}$ high) where they swiftly recovered (in less than $1 \mathrm{~h}$ ).

\section{References}

Aigueperse N, Houdelier C, Nicolle C, Lumineau S (2019) Mother-chick interactions are affected by chicks' sex and brood composition in Japanese quail. Dev Psychobiol (published online, doi:10.1002/dev.21848)

Aigueperse N, Pittet F, Nicolle C, Houdelier C, Lumineau S (2018) Maternal care affects chicks' development differently according to sex in quail. Dev Psychobiol 60:1048-1056. doi: $10.1002 / \mathrm{dev} .21597$

Akaike H (1974) A new look at the statistical model identification. IEEE Trans Autom Control 19:716-723. doi: 10.1109/TAC.1974.1100705

Archer J (1976) The organization of aggression and fear in vertebrates. In: Bateson PPG, Klopfer PH (eds) Perspectives in Ethology, vol. 2. Springer US, Boston, MA, pp 231-298

Barna I, Bálint E, Baranyi J, Bakos N, Makara GB, Haller J (2003) Gender-specific effect of maternal deprivation on anxiety and corticotropin-releasing hormone mRNA expression in rats. Brain Res Bull 62:85-91. doi: 10.1016/S0361-9230(03)00216-8

Beery AK, Francis DD (2011) Adaptive significance of natural variations in maternal care in rats: a translational perspective. Neurosci Biobehav Rev 35:1552-1561. doi: 10.1016/j.neubiorev.2011.03.012

Bell AM (2005) Behavioural differences between individuals and two populations of stickleback (Gasterosteus aculeatus). J Evol Biol 18:464-473. doi: 10.1111/j.1420-9101.2004.00817.x

Bell AM (2007) Future directions in behavioural syndromes research. Proc R Soc Lond B 274:755761. doi: 10.1098/rspb.2006.0199

Bell AM, Hankison SJ, Laskowski KL (2009) The repeatability of behaviour: a meta-analysis. Anim Behav 77:771-783 
Bell AM, Sih A (2007) Exposure to predation generates personality in threespined sticklebacks (Gasterosteus aculeatus). Ecol Lett 10:828-834. doi: 10.1111/j.1461-0248.2007.01081.x

Bell AM, Stamps JA (2004) Development of behavioural differences between individuals and populations of sticklebacks, Gasterosteus aculeatus. Anim Behav 68:1339-1348. doi: 10.1016/j.anbehav.2004.05.007

Bengston SE, Pruitt JN, Riechert SE (2014) Differences in environmental enrichment generate contrasting behavioural syndromes in a basal spider lineage. Anim Behav 93:105-110. doi: 10.1016/j.anbehav.2014.04.022

Bertin A, Richard-Yris M-A (2005) Mothering during early development influences subsequent emotional and social behaviour in Japanese quail. J Exp Zool A 303:792-801. doi: 10.1002/jez.a.202

Boon AK, Réale D, Boutin S (2007) The interaction between personality, offspring fitness and food abundance in North American red squirrels. Ecol Lett 10:1094-1104. doi: 10.1111/j.14610248.2007.01106.x

Boulay J, Chaillou E, Bertin A, Constantin P, Arnould C, Leterrier C, Calendreau L (2013) A higher inherent trait for fearfulness is associated with increased anxiety-like behaviours and diazepam sensitivity in Japanese quail. Behav Brain Res 237:124-128. doi: 10.1016/j.bbr.2012.09.026

Brommer JE, Class B (2015) The importance of genotype-by-age interactions for the development of repeatable behavior and correlated behaviors over lifetime. Front Zool 12:S2. doi: 10.1186/17429994-12-S1-S2

Budaev SV (1999) Sex differences in the Big Five personality factors: Testing an evolutionary hypothesis. Pers Indiv Diff 26:801-813. doi: 10.1016/S0191-8869(98)00179-2

Butler D, Cullis BR, Gilmour AR, Gogel BJ (2009) Asreml: asreml () fits the linear mixed model. R Package Version 3, https://www.vsni.co.uk/software/asreml-r/

Cameron EZ, Linklater WL (2000) Individual mares bias investment in sons and daughters in relation to their condition. Anim Behav 60:359-367. doi: 10.1006/anbe.2000.1480

Careau V, Thomas D, Humphries MM, Réale D (2008) Energy metabolism and animal personality. Oikos 117:641-653. doi: 10.1111/j.0030-1299.2008.16513.x

Champagne FA, Francis DD, Mar A, Meaney MJ (2003) Variations in maternal care in the rat as a mediating influence for the effects of environment on development. Physiol Behav 79:359-371

Cockrem JF (2007) Stress, corticosterone responses and avian personalities. J Ornithol 148:169-178. doi: $10.1007 / \mathrm{s} 10336-007-0175-8$

D'Amore DM, Rios-Cardenas O, Morris MR (2015) Maternal investment influences development of behavioural syndrome in swordtail fish, Xiphophorus multilineatus. Anim Behav 103:147-151. doi: 10.1016/j.anbehav.2015.02.013

Dingemanse NJ, Wright J, Kazem AJN, Thomas DK, Hickling R, Dawnay N (2007) Behavioural syndromes differ predictably between 12 populations of three-spined stickleback. J Anim Ecol 76:1128-1138. doi: 10.1111/j.1365-2656.2007.01284.x

Dochtermann NA, Dingemanse NJ (2013) Behavioral syndromes as evolutionary constraints. Behav Ecol 24:806-811. doi: 10.1093/beheco/art002 
Dufty AM, Clobert J, Møller AP (2002) Hormones, developmental plasticity and adaptation. Trends Ecol Evol 17:190-196. doi: 10.1016/S0169-5347(02)02498-9

Edelaar P, Serrano D, Carrete M, Blas J, Potti J, Tella JL (2012) Tonic immobility is a measure of boldness toward predators: an application of Bayesian structural equation modeling. Behav Ecol 23:619-626. doi: 10.1093/beheco/ars006

Edgar J, Kelland I, Held S, Paul E, Nicol C (2015) Effects of maternal vocalisations on the domestic chick stress response. Appl Anim Behav Sci 171:121-127. doi: 10.1016/j.applanim.2015.08.031

Ezard THG, Côté SD, Pelletier F (2009) Eco-evolutionary dynamics: disentangling phenotypic, environmental and population fluctuations. Phil Trans R Soc B 364:1491-1498. doi: $10.1098 /$ rstb.2009.0006

Fairbanks LA (1996) Individual differences in maternal style: causes and consequences for mothers and offspring. Adv Stud Behav 25:579-611

Fält B (1978) Differences in aggressiveness between brooded and non-brooded domestic chicks. Appl Anim Ethol 4:211-221. doi: 10.1016/0304-3762(78)90112-8

Forkman B, Boissy A, Meunier-Salaün M-C, Canali E, Jones RB (2007) A critical review of fear tests used on cattle, pigs, sheep, poultry and horses. Physiol Behav 92:340-374. doi:

10.1016/j.physbeh.2007.03.016

Formanek L, Houdelier C, Lumineau S, Bertin A, Richard-Yris MA (2008) Maternal epigenetic transmission of social motivation in birds. Ethology 114:817-826. doi: 10.1111/j.14390310.2008.01536.x

Francis DD, Meaney MJ (1999) Maternal care and the development of stress responses. Curr Opin Neurobiol 9:128-134

Francis DD, Young LJ, Meaney MJ, Insel TR (2002) Naturally occurring differences in maternal care are associated with the expression of oxytocin and vasopressin (V1a) receptors: gender differences. J Neuroendocrinol 14:349-353. doi: 10.1046/j.0007-1331.2002.00776.x

Freeman-Gallant CR, Rothstein MD (1999) Apparent heritability of parental care in Savannah sparrows. Auk 116:1132-1136. doi: 10.2307/4089694

Fresneau N, Kluen E, Brommer JE (2014) A sex-specific behavioral syndrome in a wild passerine. Behav Ecol 25:359-367. doi: 10.1093/beheco/aru008

Gosling SD (2001) From mice to men: What can we learn about personality from animal research? Psychol Bull 127:45-86. doi: 10.1037/0033-2909.127.1.45

Groothuis TGG, Maestripieri D (2013) Parental influences on offspring personality. In: Carere C, Maestripieri D (eds) Animal Personalities, University of Chicago Press. Chicago, IL, pp 317-352

Guenther A, Finkemeier M-A, Trillmich F (2014) The ontogeny of personality in the wild guinea pig. Anim Behav 90:131-139. doi: 10.1016/j.anbehav.2014.01.032

Guenther A, Trillmich F (2013) Photoperiod influences the behavioral and physiological phenotype during ontogeny. Behav Ecol 24:402-411. doi: 10.1093/beheco/ars177

Gunnar MR (1998) Quality of early care and buffering of neuroendocrine stress reactions: potential effects on the developing human brain. Prev Med 27:208-211. doi: 10.1006/pmed.1998.0276 
Han CS, Brooks RC (2013) Correlational selection does not explain the evolution of a behavioural syndrome. J Evol Biol 26:2260-2270. doi: 10.1111/jeb.12223

Harding AMA, Kitaysky AS, Hamer KC, Hall ME, Welcker J, Talbot SL, Karnovsky LJ, Gabrielsen GW, Grémillet D (2009) Impacts of experimentally increased foraging effort on the family: offspring sex matters. Anim Behav 78:321-328. doi: 10.1016/j.anbehav.2009.05.009

Hazard D, Couty M, Richard S, Guémené D (2008) Intensity and duration of corticosterone response to stressful situations in Japanese quail divergently selected for tonic immobility. Gen Comp Endocrinol 155:288-297. doi: 10.1016/j.ygcen.2007.05.009

Herrington J, Vallin C, Lickliter R (2015) Increased yolk progesterone interferes with prenatal auditory learning and elevates emotional reactivity in bobwhite quail (Colinus virginianus) chicks. Dev Psychobiol 57:255-262. doi: 10.1002/dev.21274

Hogg JT, Hass CC, Jenni DA (1992) Sex-biased maternal expenditure in Rocky Mountain bighorn sheep. Behav Ecol Sociobiol 31:243-251. doi: 10.1007/BF00171679

Hope SF, Kennamer RA, Moore IT, Hopkins WA (2018) Incubation temperature influences the behavioral traits of a young precocial bird. J Exp Zool A Ecol Integr Physiol 329:191-202. doi: $10.1002 /$ jez. 2176

Houslay TM, Vierbuchen M, Grimmer AJ, Young AJ, Wilson AJ (2018) Testing the stability of behavioural coping style across stress contexts in the Trinidadian guppy. Funct Ecol 32:424-438. doi: $10.1111 / 1365-2435.12981$

Janczak AM, Pedersen LJ, Bakken M (2003) Aggression, fearfulness and coping styles in female pigs. Appl Anim Behav Sci 81:13-28. doi: 10.1016/S0168-1591(02)00252-6

Jones RB (1986) The tonic immobility reaction of the domestic fowl: a review. World Poultry Sci J 42:82-96. doi: 10.1079/WPS19860008

Jones RB, Mills AD, Faure JM (1991) Genetic and experiential manipulation of fear-related behavior in Japanese quail chicks (Coturnix coturnix japonica). J Comp Psychol 105:15-24

Juraska JM (1984) Sex differences in dendritic response to differential experience in the rat visual cortex. Brain Res 295:27-34. doi: 10.1016/0006-8993(84)90812-6

Kanda LL, Louon L, Straley K (2012) Stability in activity and boldness across time and context in captive Siberian dwarf hamsters. Ethology 118:518-533. doi: 10.1111/j.1439-0310.2012.02038.x

Ketterson ED, Nolan V Jr (1999) Adaptation, exaptation, and constraint: a hormonal perspective. Am Nat 154:S4-S25. doi: 10.1086/303280

Kooij E v. E d., Kuijpers AH, Schrama JW, van Eerdenburg FJCM, Schouten WGP, Tielen MJM (2002) Can we predict behaviour in pigs?: Searching for consistency in behaviour over time and across situations. Appl Anim Behav Sci 75:293-305. doi: 10.1016/S0168-1591(01)00203-9

Koolhaas JM, Korte SM, de Boer SF, Van der Vegt BJ, Van Reenen CG, Hopster H, De Jong IC, Ruis MA, Blokhuis SJ (1999) Coping styles in animals: current status in behavior and stressphysiology. Neurosci Biobehav Rev 23:925-935. doi: 10.1016/S0149-7634(99)00026-3

Laurence A, Houdelier C, Calandreau L, Arnould C, Favreau-Peigné A, Leterrier C, Boissy A, Lumineau S (2015) Environmental enrichment reduces behavioural alterations induced by chronic stress in Japanese quail. Animal 9:331-338. doi: 10.1017/S1751731114002523 
Lickliter R, Harshaw C (2010) Canalization and malleability reconsidered: The developmental basis of phenotypic stability and variability. In: Hood KE, Halpern CT, Greenberg G, Lerner RM (eds) Handbook of developmental science, behavior, and genetics. Blackwell Publishing, New York, pp 491-525

Macrì S, Würbel H (2006) Developmental plasticity of HPA and fear responses in rats: A critical review of the maternal mediation hypothesis. Horm Behav 50:667-680. doi: 10.1016/j.yhbeh.2006.06.015

Marshall DJ, Uller T (2007) When is a maternal effect adaptive? Oikos 116:1957-1963. doi: 10.1111/j.2007.0030-1299.16203.x

McIntosh J, Anisman H, Merali Z (1999) Short- and long-periods of neonatal maternal separation differentially affect anxiety and feeding in adult rats: gender-dependent effects. Brain Res Dev Brain Res 113:97-106

Mignon-Grasteau S, Roussot O, Delaby C et al (2003) Factorial correspondence analysis of fearrelated behaviour traits in Japanese quail. Behav Process 61:69-75. doi: 10.1016/S03766357(02)00162-6

Mills AD, Crawford LL, Domjan M, Faure JM (1997) The behavior of the japanese or domestic quail Coturnix japonica. Neurosci Biobehav Rev 21:261-281. doi: 10.1016/S0149-7634(96)00028-0

Moore CL, Morelli GA (1979) Mother rats interact differently with male amd female offspring. J Comp Physiol Psychol 93:677-684. doi: 10.1037/h0077599

Moreno E, Pérez-Martínez C, Conde-Porcuna JM (2019) Dispersal of rotifers and cladocerans by waterbirds: seasonal changes and hatching success. Hydrobiologia 834:145-162. doi: 10.1007/s10750-019-3919-6

Morrison KE, Rodgers AB, Morgan CP, Bale TL (2014) Epigenetic mechanisms in pubertal brain maturation. Neuroscience 264:17-24. doi: 10.1016/j.neuroscience.2013.11.014

Nakagawa S, Gillespie DOS, Hatchwell BJ, Burke T (2007) Predictable males and unpredictable females: sex difference in repeatability of parental care in a wild bird population. J Evol Biol 20:1674-1681. doi: 10.1111/j.1420-9101.2007.01403.x

Nakayama S, Sasaki K, Matsumura K, Lewis Z, Miyatake T (2012) Dopaminergic system as the mechanism underlying personality in a beetle. J Insect Physiol 58:750-755. doi:

10.1016/j.jinsphys.2012.02.011

Nephew B, Murgatroyd C (2013) The role of maternal care in shaping CNS function. Neuropeptides 47:371-378. doi: 10.1016/j.npep.2013.10.013

Oomen CA, Girardi CEN, Cahyadi R, Verbeek EC, Krigers H, Joëls M,Lucassen PJ (2009) Opposite effects of early maternal deprivation on neurogenesis in male versus female rats. PLoS ONE 4:e3675. doi: 10.1371/journal.pone.0003675

Orcutt FS Jr, Orcutt AB (1976) Nesting and parental behavior in domestic common quail. Auk 93:135-141

Perré Y, Wauters A-M, Richard-Yris M-A (2002) Influence of mothering on emotional and social reactivity of domestic pullets. Appl Anim Behav Sci 75:133-146. doi: 10.1016/S01681591(01)00189-7 
Phillips PC, Arnold SJ (1999) Hierarchical comparison of genetic variance-covariance matrices. I. Using the Flury hierarchy. Evolution 53:1506-1515. doi: 10.1111/j.1558-5646.1999.tb05414.x

Pittet F (2012) Comportement maternel chez la caille japonaise (Coturnix c. japonica) : caractérisation, facteurs de variation et conséquences sur les jeunes. $\mathrm{PhD}$ thesis, Rennes 1

Pittet F, Coignard M, Houdelier C, Richard-Yris MA, Lumineau S (2012) Age affects the expression of maternal care and subsequent behavioural development of offspring in a precocial bird. PLoS ONE 7:e36835. doi: 10.1371/journal.pone.0036835

Pittet F, Houdelier C, de Margerie E, LeBot O, Richard-Yris MA, Lumineau S (2014a) Maternal styles in a precocial bird. Anim Behav 87:31-37. doi: 10.1016/j.anbehav.2013.10.025

Pittet F, Houdelier C, Lumineau S (2014b) Precocial bird mothers shape sex differences in the behavior of their chicks. J Exp Zool A 321:265-275. doi: 10.1002/jez.1858

Pittet F, Le Bot O, Houdelier C, Richard-Yris MA, Lumineau S (2014c) Motherless quail mothers display impaired maternal behavior and produce more fearful and less socially motivated offspring. Dev Psychobiol 56:622-634. doi: 10.1002/dev.21129

Réale D, Reader SM, Sol D, McDougall PT, Dingemanse NJ (2007) Integrating animal temperament within ecology and evolution. Biol Rev 82:291-318. doi: 10.1111/j.1469-185X.2007.00010.x

Richard-Yris M-A (1994) Comportement parental chez les gallinacés : importance du facteur émotivité sur la vitesse d'émergence des réponses parentales : apport du modèle caille japonaise. In: Picard, M. \& Porter J.S.P.R. (eds) Comportement et adaptation des animaux domestiques aux contraintes de l'élevage : bases techniques du bien-être animal, INRA Edition., Paris, pp 61-76

Roden C, Wechsler B (1998) A comparison of the behaviour of domestic chicks reared with or without a hen in enriched pens. Appl Anim Behav Sci 55:317-326. doi: 10.1016/S01681591(97)00073-7

Schuett W, Dall SRX (2009) Sex differences, social context and personality in zebra finches, Taeniopygia guttata. Anim Behav 77:1041-1050. doi: 10.1016/j.anbehav.2008.12.024

Schuett W, Tregenza T, Dall SRX (2010) Sexual selection and animal personality. Biol Rev 85:217246. doi: 10.1111/j.1469-185X.2009.00101.X

Schwagmeyer PL, Mock DW (2003) How consistently are good parents good parents? Repeatability of parental care in the house sparrow, Passer domesticus. Ethology 109:303-313. doi: 10.1046/j.1439-0310.2003.00868.x

Shimmura T, Kamimura E, Azuma T, Kansaku N, Uetake K, Tanaka T (2010) Effect of broody hens on behaviour of chicks. Appl Anim Behav Sci 126:125-133. doi: 10.1016/j.applanim.2010.06.011

Sih A, Bell A, Johnson JC (2004) Behavioral syndromes: an ecological and evolutionary overview. Trends Ecol Evol 19:372-378. doi: 10.1016/j.tree.2004.04.009

Sih A, Cote J, Evans M, Fogarty S, Pruitt J (2012) Ecological implications of behavioural syndromes. Ecol Lett 15:278-289. doi: 10.1111/j.1461-0248.2011.01731.x

Stamps J, Clark A, Kus B, Arrowood P (1987) The effects of parent and offspring gender on food allocation in budgerigars. Behaviour 101:177-199. doi: 10.1163/156853987X00422 
Taylor JH, Mustoe AC, French JA (2014) Behavioral responses to social separation stressor change across development and are dynamically related to HPA activity in marmosets. Am J Primatol 76:239-248. doi: 10.1002/ajp.22228

Toms CN, Echevarria DJ, Jouandot DJ (2010) A methodological review of personality-related studies in fish: focus on the shy-bold axis of behavior. Int J Comp Psychol 23:1-25

Trillmich F, Günther A, Müller C, Reinhold K, Sachser N (2015) New perspectives in behavioural development: adaptive shaping of behaviour over a lifetime? Front Zool 12:S1. doi: 10.1186/1742-9994-12-S1-S1

Urszán TJ, Garamszegi LZ, Nagy G, Hettyey A, Török J, Herczeg G (2015) No personality without experience? A test on Rana dalmatina tadpoles. Ecol Evol 5:5847-5856. doi: 10.1002/ece3.1804

van Hasselt FN, Tieskens JM, Trezza V, Krugers HJ, Vanderschuren LJ, Joëls M (2012) Within-litter variation in maternal care received by individual pups correlates with adolescent social play behavior in male rats. Physiol Behav 106:701-706. doi: 10.1016/j.physbeh.2011.12.007

van Oers K, de Jong G, van Noordwijk AJ, Kampenaers B, Drent PJ (2005) Contribution of genetics to the study of animal personalities: a review of case studies. Behaviour 142:1185-1206

van Overveld T, Careau V, Adriaensen F, Matthysen E (2014) Seasonal- and sex-specific correlations between dispersal and exploratory behaviour in the great tit. Oecologia 174:109-120. doi: $10.1007 / \mathrm{s} 00442-013-2762-0$

Vos DR (1995) The role of sexual imprinting for sex recognition in zebra finches: a difference between males and females. Anim Behav 50:645-653. doi: 10.1016/0003-3472(95)80126-X

Webster DG, Lanthorn TH, Dewsbury DA, Meyer ME (1981) Tonic immobility and the dorsal immobility response in twelve species of muroid rodents. Behav Neural Biol 31:32-41. doi: 10.1016/S0163-1047(81)91034-7

Wigger A, Neumann ID (1999) Periodic maternal deprivation induces gender-dependent alterations in behavioral and neuroendocrine responses to emotional stress in adult rats. Physiol Behav 66:293302

Wilson ADM, Krause J (2012) Personality and metamorphosis: is behavioral variation consistent across ontogenetic niche shifts? Behav Ecol 23:1316-1323. doi: 10.1093/beheco/ars123

Wuerz Y, Krüger O (2015) Personality over ontogeny in zebra finches: long-term repeatable traits but unstable behavioural syndromes. Front Zool 12:S9. doi: 10.1186/1742-9994-12-S1-S9 